suggested by Oka and colleagues. ${ }^{3}$ The authors found that patients with BE have significant suppression of T-cell and B-cell function as well as interlukin-2 production. In addition, Hsu and associates ${ }^{4}$ reported a case of metastatic esophageal cancer arising in $\mathrm{BE}$ in a patient with chronic lymphocytic leukemia with documented B-cell dysfunction. In the present report, the use of induction therapy followed by intense immunosuppression certainly placed the BE at increased risk for malignant transformation.

It is possible that the metaplasia in this patient may have progressed into high-grade dysplasia prior to the transplantation, taking into consideration the 22-month gap between the diagnosis of metaplasia and the transplant. Endoscopic surveillance during the waiting period would have permitted an early diagnosis; however, this was not possible in view of the patient's poor pulmonary status.

Only one case of rapid progression of BE to adenocarcinoma has been reported after liver transplantation, ${ }^{5}$ and to our knowledge, the present case is the first reported after lung transplantation.
It becomes essential to ask whether the diagnosis of $\mathrm{BE}$ in pretransplant patients precludes them from being transplanted. Although there is no clear answer, there is no doubt that these patients should undergo upper gastrointestinal endoscopy on a regular basis prior to their transplant. Close surveillance after transplantation is certainly warranted to detect signs of dysplasia. Should high-grade dysplasia occur, adjustment of the immunosuppressive therapy is necessary and ablation or resection of the dysplastic mucosa should be considered.

\section{References}

1. Andrés A. Cancer incidence after immunosuppressive treatment following kidney transplantation: a review. Crit Rev Oncol Hematol. 2005;56:71-85.

2. Ippoliti G, Rinaldi M, Pellegrini C, Vigano M. Incidence of cancer after immunosuppressive treatment for heart transplantation: a review. Crit Rev Oncol Hematol. 2005;56:101-13.

3. Oka M, Attwood SE, Kaul B, Smyrk TC, DeMeester TR. Immunosuppression in patients with Barrett's esophagus. Surgery. 1992;112:11-7.

4. Hsu CW, Krevsky B, Sigman LM, Thomas RM. Rapid progression of Barrett's esophagus to metastatic esophageal carcinoma in a patient with chronic lymphocytic leukemia. J Clin Gastroenterol. 1998;27:261-4.

5. Ilan Y, Shouval D, Galun E, et al. Esophageal malignancy after liver transplantation in a patient with Barrett's esophagus. Scand J Gastroenterol. 1996;31:415-6.

\title{
Nonobstructive ectopic accessory mitral valve tissue in association with left ventricular apical aneurysm
}

\author{
Lokeswara Rao Sajja, MS, MCh, MD, FACS, and Gopichand Mannam, FRCS (Glasg), FRCS(Ed), FRCS \\ (CT), Hyderabad, India
}

Accessory mitral valve tissue is a rare congenital cardiac anomaly, an uncommon cause of left ventricular outflow tract (LVOT) obstruction, and usually diagnosed during childhood. We report a case of a nonobstructive accessory mitral valve in a 33-year-old woman who was evaluated for systemic embolization that resulted in right hemiplegia. A mass lesion was diagnosed in the apical region of the left ventricular (LV) cavity by means of transthoracic and transesophageal echocardiography. A cardiac magnetic resonance image (MRI) showed a mass lesion in the LV cavity and LV apical aneurysm. The patient had undergone suc-

From the Lung Transplantation Program, Division of Thoracic Surgery, Centre Hospitalier de l'Universite de Montreal, Montreal, Quebec, Canada.

Received for publication April 9, 2008; revisions received April 24, 2008; accepted for publication May 20, 2008; available ahead of print Sept 16, 2008.

Address for reprints: Gopichand Mannam, FRCS (Glasg), FRCS(Ed), FRCS (CT), Department of Cardiothoracic Surgery, CARE Hospital, the Institute of Medical Sciences, Road No.1 Banjara Hills, Hyderabad, Andhra Pradesh 500034, India (E-mail: gopi.mannam@gmail.com).

J Thorac Cardiovasc Surg 2010;139:218-20

$0022-5223 / \$ 36.00$

Copyright (c) 2010 by The American Association for Thoracic Surgery doi:10.1016/j.jtcvs.2008.05.057 cessful excision of the mass lesion, which was accessory mitral valve tissue, and linear repair of the LV aneurysm.

\section{CLINICAL SUMMARY}

A 33-year-old woman who recovered from right hemiplegia was referred to our center with a diagnosis of an intracavitory mass lesion of the left ventricle. On physical examination, she had a regular pulse, with a rate of 80 beats/min and a blood pressure of $126 / 80 \mathrm{~mm} \mathrm{Hg}$. Her first and second heart sounds were normal, and there was no murmur. An electrocardiogram showed sinus rhythm. She was evaluated with transthoracic and transesophageal 2-dimensional echocardiography and Doppler scanning, which showed a mass in the LV cavity, and there was no gradient across the LVOT. A cardiac MRI demonstrated a mass lesion in the LV cavity attached to the distal interventricular septum and LV apical aneurysm (Figure 1, A). A coronary angiogram showed normal epicardial coronary arteries.

She underwent excision of accessory mitral valve tissue and linear repair of the LV aneurysm through a standard median sternotomy during cardiopulmonary bypass. The 

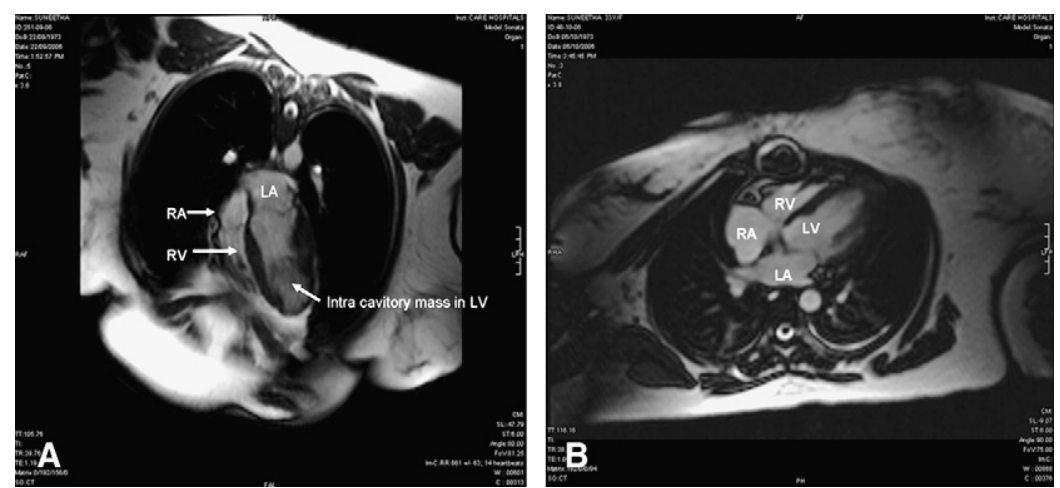

FIGURE 1. A, Preoperative cardiac magnetic resonance imaging 4-chamber view showing a normal mitral valve and a mass lesion in the left ventricular cavity extending into the left ventricular apex, which is aneurysmal. B, Postoperative cardiac magnetic resonance imaging 4-chamber view showing no residual mass lesion in the left ventricular cavity and a normal mitral valve. $L A$, Left atrium; $R A$, right atrium; $L V$, left ventricle; $R V$, right ventricle.

myocardial protection was achieved with moderate hypothermia and antegrade cold blood cardioplegia. The mass lesion of the LV cavity was approached through the left ventriculotomy made through the aneurysm (Figure 2, A), and the mass lesion, which looked like accessory mitral valve tissue (Figure 2, $B$ ), was attached to the interventricular septum and was not connected to the normal mitral valve, which makes it ectopic accessory mitral valve tissue. The accessory tissue was excised in toto without damaging the adjacent structures. The postoperative cardiac MRI showed no residual mass lesion in the LV cavity and a normally functioning mitral valve (Figure 1, B). Postoperatively, warfarin and acetylsalicylic acid therapy were discontinued because there was no clot in the left ventricle. The histopathologic examination of the wall of the aneurysm was suggestive of scar tissue but not of a diverticulum.

\section{DISCUSSION}

There have been about 50 cases of accessory mitral valve tissue reported in the medical literature ever since the first case was reported by MacLean and associates. ${ }^{1}$ In about two thirds of cases, the accessory mitral valve was associated with other cardiac anomalies, and symptoms had developed during infancy or early childhood. ${ }^{2,3}$ The LVOT obstruction is usually the mark of this anomaly, and only on 3 occasions was it not associated with obstruction of the LVOT. ${ }^{4}$ Accessory mitral valve is an uncommon feature in an adult patient, and the accessory valve tissue is usually recognized during the surgical procedure..$^{5}$ There are, however, no reported cases of systemic embolization caused by accessory mitral valve tissue or its association with a left ventricular aneurysm. The widespread use of 2-dimensional echocardiography and color Doppler scanning has greatly improved the accuracy of diagnosis of intracavitory mass lesions of the left ventricle. An MRI is collaborative in delineating the morphologic details of the accessory mitral valve tissue.

In the present case in the presence of a mass lesion in the LV cavity, we had presumed preoperatively that the mass lesion could be a ventricular myxoma, but the morphologic features noticed at the time of the operation and histopathologic examination revealed the mass lesion to be accessory mitral valve tissue. The associated apical aneurysm was of the congenital variety and was not associated with a stenotic lesion of the epicardial coronary arteries. To the best of our knowledge, a congenital LV aneurysm in association with accessory mitral valve tissue has not been reported in the English literature in the past. Excision of the accessory mitral valve tissue can be performed safely through a ventriculotomy made through
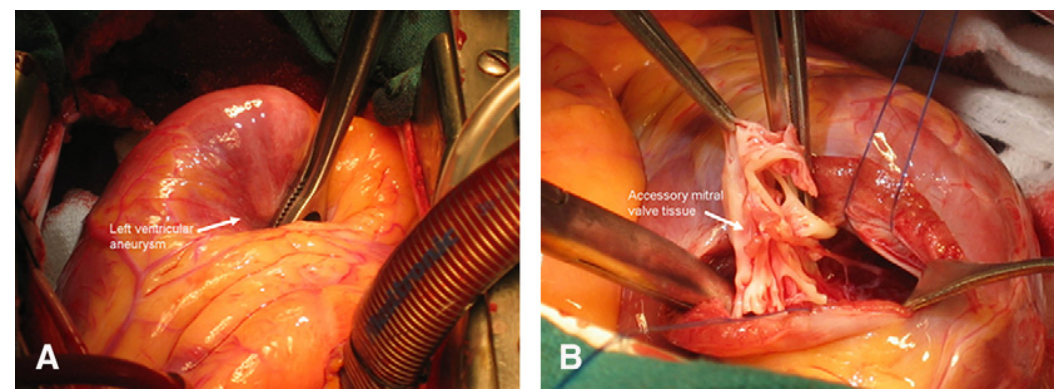

FIGURE 2. A, Intraoperative photograph showing the thinned-out and indented part of the anterior wall of the left ventricle, which is aneurysmal. B, Intraoperative photograph showing accessory mitral valve tissue attached to the distal part of the interventricular septum and papillary muscle of the mitral valve. 
the wall of the aneurysm without damaging the adjacent structures.

\section{References}

1. MacLean L, Culling JA, Kane DJ. Subaortic stenosis due to accessory tissue on the mitral valve. J Thorac Cardiovasc Surg. 1963;45:382-8.
2. Yoshimura N, Yamaguchi M, Oshima Y, Oka S, Ootaki Y, Tei T, et al. Clinical and pathological features of accessory valve tissue. Ann Thorac Surg. 2000;69:1205-8.

3. Sajja LR, Mannam GC, Sompalli S, Missula SK. Accessory mitral valve tissue obstructing left ventricular outflow tract. Asian Cardiovasc Thorac Ann. 2001;9:325-6.

4. Izumoto H, Ishihara K, Ogawa M, Fujii Y, Oyama K, Kawazoe K. Nonobstructing accessory mitral valve tissue and ventricular septal defect. Ann Thorac Surg. 1996; 62:1846-8

5. Costa J, Almeida J, Barreiros F, Sousa R. Accessory mitral valve as cause of left ventricular obstruction in the adult. J Thorac Cardiovasc Surg. 2003;125:1531-2. 